\title{
Marketing Strategy for Hotel and Tourist Complex Companies
}

\author{
Submitted 08/02/19, 1st revision 13/03/19, 2nd rervision 22/04/19, accepted 04/06/19
}

\author{
Bondarenko V.A. ${ }^{1}$, Efremenko I.N. ${ }^{2}$, Larionov V.A. ${ }^{3}$
}

\begin{abstract}
:
Purpose: The article aims at justifying the application of certain marketing strategies by hotel and tourist companies. The choice of marketing strategies is variable and depends on the potential, resource support and the specifics of the target consumer audience.

Design/Methodology/Approach: To substantiate the marketing strategies demanded in the current situation, it seems necessary: first, to explore the emerging trends in the demand for tourism infrastructure, the demand for hotel services, estimated on the basis of general trends in tourism development; second, to assess the presence of marketing technologies, including in the framework of innovative marketing in the analyzed area, as well as the use of marketing strategies in building relationships with target audiences; third, to formulate recommendations on the choice of a marketing strategy, taking into account the capabilities and targets of the hotel company.

Findings: The authors proposed general recommendations on the choice of the marketing strategy of a hotel and tourism company, based on its resource capabilities, goals and specifics of the existing or potentially interesting target segment. The conclusion is made about the need for continuous innovation in the framework of building relationships and customer service.

Practical Implications: The findings could be incorporated into the management system of hotel enterprises when planning marketing programs.

Originality/Value: The main contribution of the study is to focus on the competitiveness of a hotel and tourist company on a research marketing function aimed at choosing the direction of strategic development of activities and introducing innovations into the daily practice.
\end{abstract}

Keywords: Hotel and tourist complex companies, national tourist rating, marketing strategies.

JEL Code: L83, L10, L29.

Paper Type: Research article in Special Issue dedicated to Russian Economy.

Section 8: Business and Economic Issues.

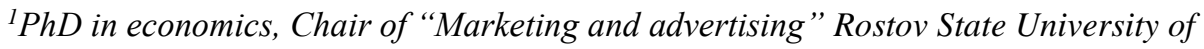
Economics, Rostov-on-Don, b14v@yandex.ru

${ }^{2}$ PhD in economics, Professor of "Financial monitoring and financial markets" Rostov State University of Economics, Rostov-on-Don, efremenko@yandex.ru

${ }^{3}$ Applicant of Chair of "Marketing and advertising” Rostov State University of Economics, Rostov-on-Don, OET2004@yandex.ru
} 


\section{Introduction}

The interest in marketing measures in hotel and tourist complex in Russia is actualized by competition among market participants providing services to this sector. The influence of the state initiating the development of tourism both domestic and inbound, is no less significant in this aspect, which is naturally associated with the improvement of the entire infrastructure (especially the accommodation infrastructure) and the improvement of the quality of tourist services. On a national scale, in this connection, ambitious goals are set for the formation of a "tourist infrastructure intersected with the Spatial Development Strategy of the Russian Federation for the period up to 2025 and a comprehensive plan for the modernization and expansion of the trunk infrastructure, including the use of public-private partnership mechanisms, and creating conditions for the implementation of private infrastructure projects; brand-new industry management through expanding forms of interaction with participants of the tourist market, supporting the creation and development of industry associations, improving the system of monitoring and statistical accounting, strengthening public control measures in the industry; development in partnership with market participants of the industry-wide system of training and raising the level of skills for tourism industry specialists; ensuring an increase in the number of foreign tourists visiting the Russian Federation to increase the export volume of travel services up to $\$ 15.5$ billion (1.73 times compared to 2017 ) (Main Directions, 2018).

The provision of high-quality tourist services involves the active use of marketing tools and the development of a marketing strategy for working with selected consumer segments at the moment and exploring possible prospects in a prolonged time span.

In this connection, the study and identification of the main directions of application of marketing strategies in the hotel and tourism companies and events within the framework of marketing management, taking into account the basic data of the tourism industry in Russia, reflected in the corresponding rating, becomes extremely relevant.

\section{Materials and Methods}

Areas like attracting customers and building their loyalty in the hotel industry are actively explored within the framework of scientific and practical studies (Velichko ans Minosyan, 2015; Velichko, 2015; Vasin, Lavrentiev et al., 2007). Marketing and its tools in tourism and hotel business, marketing management and marketing research, forecasting the development of this sector based on specialized marketing research are of certain interest as well (Bondarenko and Kozlov, 2015; Bondarenko and Kozlov, 2017; Velichko and Lukoyanova, 2007; Yakovleva-Chernyshova, 2014).

The use of marketing technologies, including in the framework of innovative marketing, as well as the use of marketing strategies in building relationships with 
target audiences in the hotel and tourism industry has been widely studied. However, due to the large dynamics of this market and the variability of consumer preferences, they require constant updating and analytical study. With the noted purpose, the methods of system analysis, logical analysis, induction, deduction, synthesis of the obtained information are utilized in this article.

\section{Results}

Marketing in the hotel-tourist companies is aimed at studying the external environment, assessing the company's own capabilities and maintaining the activity targeted at enterprises in this sector at a level that ensures proper competitiveness. This involves conducting specialized marketing research and developing a strategy for further actions, which allows concentrating efforts on a specific target audience, which allows increasing the customer satisfaction (Dzhasheev, 2016).

The active development of the tourism and recreational sector in Russia is evidenced by the growth in profitability of hotels. In 2016, they earned 418 billion rubles, and in 2017 their earnings amounted to 485 billion. For the first 9 months of 2018, the profit amounted to 406 billion rubles, whereas in the first 9 months of 2017, the profit amounted to 324 billion rubles (National tourist rating, 2018). We also note an increase in the number of tourists living in collective accommodation facilities (Figure 1).

Figure 1. Trend data in the number of Russian tourists living in collective accommodation facilities, million people

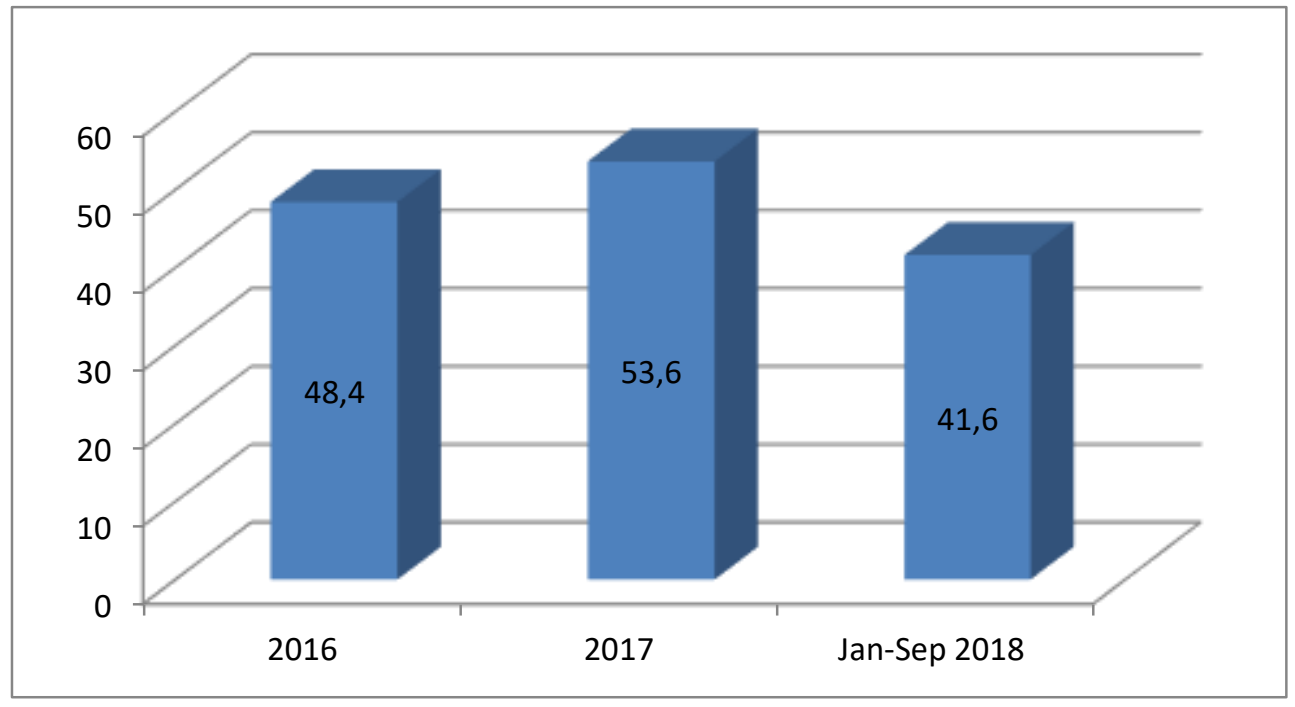

Thus, in 2016, 48.4 million Russian citizens lived in collective accommodation facilities, and in 2017 they amounted 53.6 million. In January-September 2018, 41.6 million were accommodated in hotels 36.8 million people in 2017). The number of 
foreigners staying overnight in Russian hotels also increased: by 2 million people in 2017 compared to 2016. Over January-September 2018, they amounted 7.3 million, whereas for 9 months of 2017, this figure was 6 million people (National tourist rating, 2018).

The number of collective accommodation facilities also increased in 2017 by 4757 compared to 2016 and amounted to 25291 units. Occupancy of certain accommodation facilities largely depends on the popularity of the regions they are located in. According to the national tourism rating, the following 20 regions are in the top (Table 1).

Table 1. The first twenty regions - leaders of the 2018 national tourist rating (National tourist rating, 2018)

\begin{tabular}{|c|l|c|}
\hline No & \multicolumn{1}{|c|}{ Region of the Russian Federation } & Total Points \\
\hline 1 & Moscow & 105 \\
\hline 2 & Krasnodar region & 104,4 \\
\hline 3 & Moscow region & 104 \\
\hline 4 & Saint Petersburg & 97,4 \\
\hline 5 & Republic of Crimea & 92,5 \\
\hline 6 & Altai region & 92,2 \\
\hline 7 & Sverdlovsk region & 92,1 \\
\hline 8 & Primorsky region & 92 \\
\hline 9 & Nizhny Novgorod region & 88,2 \\
\hline 10 & Republic of Bashkortostan & 88 \\
\hline 11 & Stavropol region & 85,4 \\
\hline 12 & Republic of Tatarstan & 83,8 \\
\hline 13 & Irkutsk region & 82,2 \\
\hline 14 & Perm region & 81,8 \\
\hline 15 & Chelyabinsk region & 81,2 \\
\hline 16 & Rostov region & 81,1 \\
\hline 17 & Novosibirsk region & 81 \\
\hline 18 & Tver region & 80,3 \\
\hline 19 & Tyumen region & 79,6 \\
\hline 20 & Samara region & \\
\hline
\end{tabular}

The following significant criteria were used as the basis for the national rating:

- the level of development of the hotel industry and infrastructure;

- significance of the tourism industry in the region's economy;

- profitability of the tourism industry in the region;

- level of development of the sanatorium and resort industry in the region: the volume of paid services of sanatorium and resort organizations;

- popularity of the region among tourists coming for several days;

- popularity of the region with foreigners; 
- tourist uniqueness;

- crime situation;

- online interest in the region as a place of rest;

- promotion of the tourist potential of the region in the media (National Tourist Rating, 2018).

We emphasize that the criterion for the development of the hotel industry is the most valuable one when calculating the rank of the region. In turn, the effective development of the hotel industry can be carried out on the basis of marketing strategies developed and introduced.

According to the marketing theory, it is reasonable to refer to the following main strategies applicable for hotels: undifferentiated marketing strategy; differentiated marketing strategy and a concentrated marketing strategy. When deciding on the practical use of the strategy of undifferentiated marketing, a hotel product originally intended for a wide consumer audience is created. In the case of such a strategic approach, the hotel aims to attract all possible audiences who do not make special requests to the conditions of their accommodation and a set of additional services. This allows reducing the cost of research functions and staff training. Communication costs are also assumed at the middle level, since they are focused on everyone and do not imply exclusivity (Dzhasheev, 2016).

However, following this strategy complicates the effective management of competition in modern conditions, since without sufficient differentiation it is difficult to position the business and fully satisfy consumer needs. Such a strategy can be applied at the stage of creating an enterprise and searching for its market gap, if this issue was not properly worked out at the project stage.

In implementing the strategic direction of business development within the framework of differentiated marketing, a company is focused on certain market segments. For example, it may be young couples and families with children; or student and sports groups and so on. In this case, a specific hotel product is offered, aimed at each selected segment. Following this direction implies competition with other means of accommodation, which are focused on the same target segments. In addition, it is difficult to develop sub-strategies for each target segment. Nevertheless, such an approach is justified, for example, in the off-season, when we could change priorities and develop cooperation with audiences who do not cause much interest during the peak season. When choosing a concentrated marketing strategy, the management of a collective accommodation facility selects the target segment, which is the most promising in the current or forecasted near-term outlook. Communications and the specifics of personnel training are oriented on this target audience.

This strategy can be applied in case of limited budget, when it is not possible to cover different market segments. In this case, all efforts are concentrated on a particular consumer group (Elkanova, 2015). 
Such a practical approach is justified in the activity of small and medium-sized hotels, which have limited resources, but in the case of concentrating on a specific target segment, they can seriously compete with larger industry entities attracting multidirectional audiences. The use of a concentrated marketing strategy in the development of a hotel and tourism company implies constant research on the preferences of the target segment and the proposal of certain organizational and marketing innovations that are important to the target audience.

\section{Discussion}

With the rapid development of markets and the sophistication of modern consumers, the issue of offering client innovations is relevant for collective accommodation facilities that focus on virtually any option for the strategic development of their business. Large hotels, especially chain hotels, may be the first to introduce various innovations, being innovators or pioneers in the industry; other means of collective accomodation could follow the leader and quickly adapt the innovation to their operating conditions.

Not all innovations are of high cost. For example, ordering laundry services, calling a taxi or ordering dishes to a room could be performed using a special application via smartphone and implemented in a small hotel. Part of organizational innovations could involve additional staff training and the acquisition of certain competences that are relevant for working with the target audience.

\section{Conclusion}

We note that marketing research and the choice of a specific direction of strategic development reasonable for a hotel and tourist enterprise are the key to ensuring the competitiveness. The focus on introducing innovations in the process of attracting consumers and their direct service also plays a significant role. When choosing organizational, process or marketing innovations, it is necessary to focus on making a profit from their implementation, determine their significance for representatives of the target audience and evaluate the time lag the competing organizations could introduce them. By this period, it will be necessary to produce new solutions in cooperation with consumers on the appropriate research base.

\section{References:}

Bondarenko, V.A., Kozlov, A.V. 2015. Issues of attractiveness of inbound tourism in the Rostov region on the basis of cultural and historical motive. Scientific and methodical electronic journal 'Concept', S24, 16-20.

Bondarenko, V.A., Kozlov, A.V. 2017. Issues of changing tourism flows and priorities for the development of tourism in the Russian Federation. Scientific and methodical electronic journal 'Concept', 31, 216-220.

Dzhasheev, I.K. 2016. Marketing strategies and innovations of a hotel enterprise. Young scientist, 11, 708-710.

Elkanova, D. 2015. Basics of the hospitality industry. Litres, 264. 
Main Directions. 2018. Main directions of the activities of the Government of the Russian Federation for the period until 2024, clause 1.10 Tourism. Available online: http://static.government.ru/media/files/ne0vGNJUk9SQj1GNNsXIX2d2CpCho9qS.pd f.

National tourist rating. 2018. National comprehensive rating. Available online: http://russiarating.ru/info/14699.html.

Vasin, Yu.V., Lavrentyev, L.G., Samsonov, A.V. 2007. Effective loyalty programs. How to attract and retain customers. Moscow, Alpina Publisher, 152.

Velichko, N.Yu. 2015. The need for marketing management in companies of the hotel and tourist complex. Management and economy in the 21st century, 2, 49-62.

Velichko, N.Yu., Lukoyanova, Yu.N. Marketing in tourism. 2007. Problems of sustainable development of regions of recreational specialization. Proceedings of the scientific and practical conference. Sochi, RIO SNIC RAS, 276.

Velichko, N.Yu., Minosyan, S.D. 2013. Marketing activities to improve consumer loyalty to the hotel and tourism product, 6, 47-52.

Yakovleva-Chernysheva, A.Yu. 2014. Marketing in entrepreneurial activity as an object of management. Humanization of education, 2, 62-88. 